\title{
Evaluation of Hand Sanitizer for On-Site Disinfection of Mouthguards
}

\author{
Eugene J Whitaker*, Naser SM Al Anezi and Cemil Yesilsoy \\ Kornberg School of Dentistry at Temple University, USA
}

Submission: February 21, 2019; Published: March 28, 2019

*Corresponding author: Eugene J Whitaker, DMD, PhD, Associate Professor Emeritus, Kornberg School of Dentistry at Temple University, 3223 N. Broad St., Philadelphia, Pa 19140, USA

Abstract

The oral cavity may be an important and overlooked reservoir of systemic infection, and athletic appliances may constitute a potentially important and under-recognized risk factor for infection. Athletic appliances are not disinfected routinely at home and there is no specific clinical protocol for the control of bacterial biofilm on these appliances. Many athletic mouthguards are often left in the locker room, and while in use at the athletic site, are often transferred from the mouth to hands, and temporarily stored or carried at distant sites (e.g., helmets, shorts, sleeves, socks etc.). Athletic mouthguards may be colonized not only with oral bacteria, but also the prominent skin pathogen Staphylococcus aureus, which is often transmitted from the colonized site to a site of subsequent infection. Therefore, the purpose of this study was to assess a widely used hand disinfectant as an alternative method of disinfecting acrylic mouthguard specimens contaminated with oral, skin, and gastrointestinal microorganisms, having in mind its possible use at the athletic site and in the locker-room.

Keywords: Disinfection; Mouthguard; Hand sanitizer

\section{Introduction}

Oral devices, e.g. toothbrushes, mouthguards and dentures, can transmit organisms responsible for both local and systemic disease [1]. Home-based sanitation procedures that are effective for cleaning toothbrushes, e.g. rinsing with soap and water, mouth rinses, and microwave irradiation, are not convenient for sanitizing mouthguards at the athletic site.

Oral appliances become colonized by microorganisms after a certain time in the mouth [2]. Gram-positive cocci, gram-positive bacilli, gram-negative cocci, gram-negative bacilli, yeasts, and molds were isolated from 81 athletic mouthguards submitted for microbial analysis [3]. The two most frequently gram-positive cocci isolated from athletic mouthguards were Staphylococcus aureus and Staphylococcus epidermidis, prominent skin pathogens that are also associated with endocarditis, pericarditis, pneumonia, osteomyelitis, food intoxication, and athletic equipment contamination [4].

The oral cavity may be an important and overlooked reservoir of systemic infection, and athletic appliances may constitute a potentially important and under-recognized risk factor for infection [5]. The possible disease transmission by contaminated athletic mouthguards, one to a leg abscess and another to lung infection, has been documented in two young football players [6]. The oral cavity is commonly colonized with $S$. aureus which may be associated with a wide range of serious infections, especially methicillin-resistant S. aureus (MRSA) [7], Athletes have been the subject of an increasing number of reported MRSA cases [8].
Methicillin-resistant $S$. aureus is an important nosocomial pathogen, which is often transmitted from the colonized site to the site of subsequent infection and is responsible for considerable morbidity and mortality. Two types of MRSA are identified in the literature: hospital-associated MRSA and community associated MRSA. An increase in community associated MRSA (aka close-quarter MRSA) outbreaks has been noted in basketball, football, rugby, volleyball, and wrestling athletes. and some strains of S. aureus are the most common cause of cultured skin abscesses in athletes [9]. Among athletes, MRSA may be spread from skin to skin contact with open abrasions and contaminated persons, from surface to skin contact with contaminated sports equipment (e.g. mouthguards), or by sharing personal items [9].

Good personal hygiene is the key to prevention and control of community associated MRSA outbreaks. Such practices among athletes include the following: frequent hand washing, covering abrasions or seeping wounds, disallowing athletes with open wounds in whirlpools or saunas, discouraging shared personal items, requiring showers after all practices and games, wearing sandals in showers, isolating athletes who have infections, and washing protective gear after each use [10]. Recommended infection control measures include regular and thorough cleaning of equipment, however when antimicrobial treatment is recommended, specific products are not identified.

Athletic mouthguards are difficult to clean and provide retentive sites for microorganisms. Although adequate brushing or 
scrubbing with a dentifrice is an effective means of controlling the biofilm, inappropriate home-care quality and frequency are factors that compromise the efficacy of the mechanical control of biofilm on mouthguards [11]. In addition, many athletic mouthguards are often left in the locker room, and while in use at the athletic site, are often transferred from the mouth to hands, and temporarily stored or carried at distant sites (e.g. helmets, shorts, sleeves, socks etc.). Alternative means of disinfecting mouthguards at the athletic site may include the use of hand sanitizer. Therefore, the purpose of this study was to assess this alternative method of disinfecting samples of acrylic from surface inoculates of specific bacteria.

\section{Materials and Methods}

Bacterial cultivation and preparation of cells. Staphylococcus epidermidis (aka S. aureus), Lactobacillus casei, and Escherichia coli were purchased from the American Type Culture Collection, Manasas, Va. S. epidermidis ATCC 12228 was grown on/in brain heart infusion agar and broth. L. casei (aka L. rhamnosus) ATCC 7469 was grown on/in Lactobacillus agar and broth. E. coli ATCC 10798 was grown on/in trypticase soy agar/broth. The purchased freeze dried cells were reconstituted in their respective broths and then streaked on agar plates. Colonies were examined for purity and single colonies were transferred to broth and grown to log phase (4hrs) at which time they were used experimentally.

\section{Experimental set-up}

All experiments were conducted in a laminar control hood (Environmental Air Control, Inc., Hagerstown, Md). The surface of the hood was disinfected with Clorox wipes prior to conducting the experiments. All tubes, broths, agars and pipet tips were sterilized by autoclaving at $121 \mathrm{C}$ for 20 minutes.

\section{Materials to be tested}

Purell $^{\mathrm{TM}}$ and Clorox were purchased from local pharmacies. Clorox was diluted to $2 \%$.

\section{Preparation of acrylic specimens}

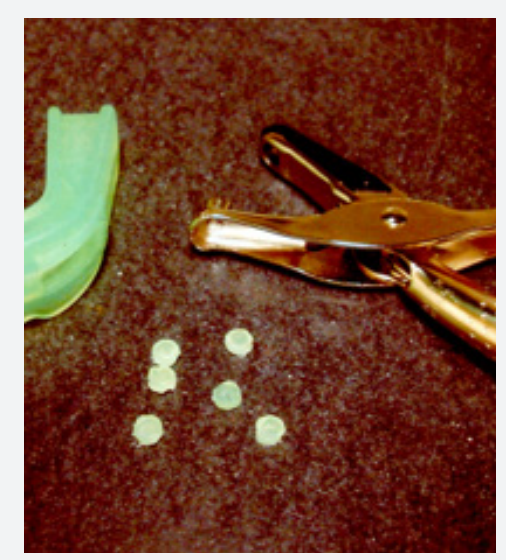

Figure 1: Discs Were Prepared from Night Guard. A standard hole puncher was used to make circular discs from a hard-soft acrylic mouth guard. Disc sizes were approximately $6 \mathrm{~mm}$ wide in diameter and $2.5 \mathrm{~mm}$ thick.
A standard hole puncher was used to make circular discs from a hard-soft acrylic mouth guard (Figure 1). Disc sizes were polished so that they were $6 \mathrm{~mm}$ wide in diameter, $2.5 \mathrm{~mm}$ thick and weighed $1 \mathrm{~g}$. The cut discs were sterilized by autoclaving at $121 \mathrm{C}$ for $20 \mathrm{~min}$.

\section{Experimental Procedure for Evaluating the Effect of Hand Sanitizer on Mono-species Bioflms of S. epidermi- di., E. coli, and L. casei.}

The effect of a 20 second exposure to Purell ${ }^{\mathrm{TM}}$ on single species biofilm vitality was measured like the method of Welch et al. [12] as follows:

Formation of biofilms: Mono-species biofilms could form on the surface of the discs by incubating them in cells growing through log phase for $4 \mathrm{hrs}$ at $37 \mathrm{C}$ with agitation. A disc immersed in sterile broth (no cells) was used as negative control. (For quality control, biofilms attached to 10 separate discs were stained with crystal violet [a dye that is specifically taken up by gram positive bacteria]. Distaining with 30\% acetic acid confirmed that all discs retained similar numbers of bacteria).

Rinsing: After the experimental discs were removed using sterile procedures, planktonic cells were removed by rinsing with $5 \mathrm{ml}$ sterile saline, vortexing for $10 \mathrm{sec}$ in $1 \mathrm{ml}$ sterile saline, and rinsing again with $5 \mathrm{ml}$ sterile saline.

Treatment: Discs with adherent cells were then dipped into sterile Eppendorf tubes containing $1 \mathrm{ml}$ of the following: sterile saline (positive control), Purell ${ }^{\mathrm{TM}}$, or $2 \%$ sodium hypocholorite (Clorox) for 20 seconds. All discs were then rinsed once with $1 \mathrm{ml}$ sterile saline.

Allowing biofilm cells to recover: Discs were placed into $10 \mathrm{ml}$ replenished media. All four tubes of broth containing the discs (designated as working solutions) were then incubated at $37 \mathrm{C}$ for 24 hours. Growth curves were generated for all four specimens, i.e. negative control, positive control, disc dipped into Purell $^{\mathrm{TM}}$, and disc dipped into Chlorox., by withdrawing samples and measuring turbidity on a spectrophotometer at $400 \mathrm{~nm}$.

Assessing biofilm cell viability: In addition to growth curves, after 4 hrs incubation, samples from each working solution were diluted in ten-fold steps for the purpose of estimating bacterial cell numbers. From the dilutions, $0.1 \mathrm{ml}$ was spread evenly across the surface of their respective agars. All agar plates were incubated for $48 \mathrm{hrs}$. at $37 \mathrm{C}$, after which all visible colonies were counted. The number of colonies forming units (CFU) were determined by counting segments of the plates like the procedure described Loeshe et al. [13]. All experiments were performed in triplicate.

Statistical analysis: The Student t-test was used to compare means of colony firming units between positive control samples and experimental Purell ${ }^{\mathrm{TM}}$ samples.

Results

Figure 2 shows the growth curves for $S$. aureus generated by cells attached to acrylic discs inserted into replenished media. Similar curves were found for L. casei and E. coli (data not shown). 
Discs treated with Purell ${ }^{\mathrm{TM}}$ showed diminished growth patterns, with significantly less surviving colony forming units, as seen in Figures 3-5. The results of the surface application experiments for all three organisms are summarized in Table 1. As compared to positive control, surface application of hand sanitizer (Purell ${ }^{\mathrm{TM}}$ ) for $20 \mathrm{sec}$ significantly inhibited growth of all three bacteria ( $\mathrm{p}$ $<0.05$ ). Three trials also indicated that mixing of $2 \%$ sodium hypochlorite (Clorox) with the bacterial inoculum on the surface of discs for 20 seconds completely inhibited growth of all three organisms.

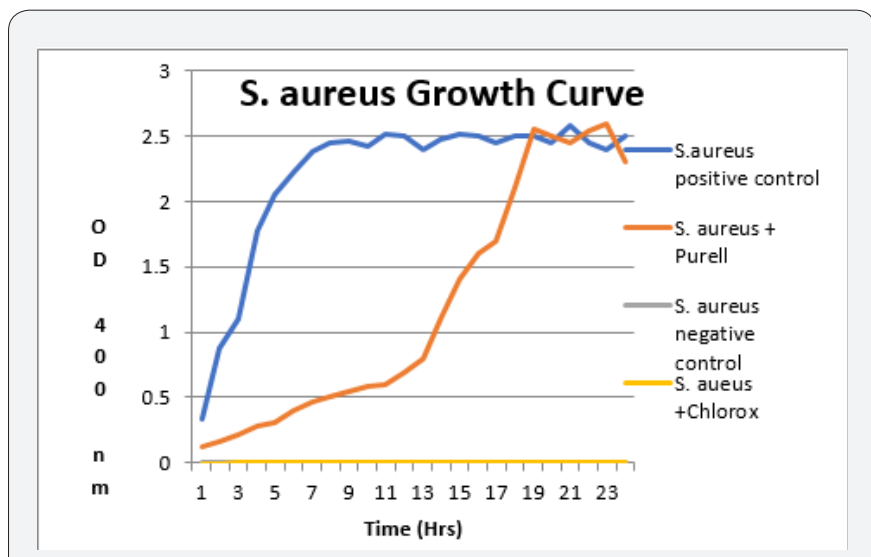

Figure 2: Growth curve of S. aureus. The positive control growth curve demonstrates viability of biofilm cells on acrylic discs. Discs treated with Purell ${ }^{\mathrm{TM}}$ and Chlorox have diminished growth.
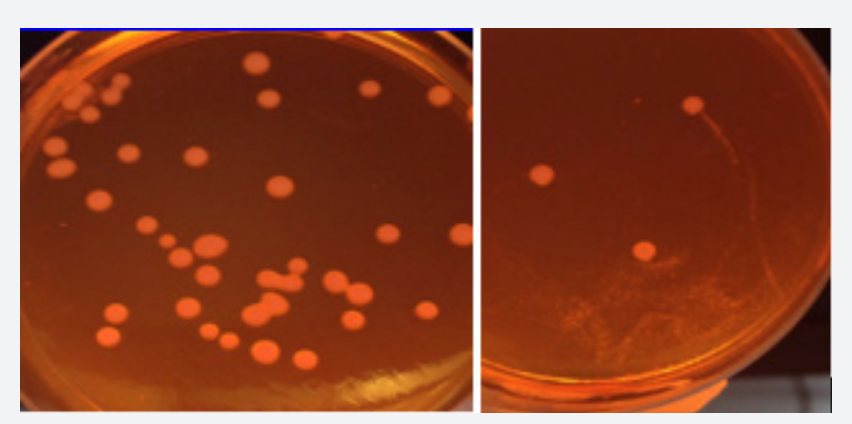

Figure 3: L. casei applied to surface of discs and treated with hand sanitizer. $10^{-6}$ Serial Dilution Plates of L. casei: left, + control; right, Purell ${ }^{\mathrm{TM}}$ treated.

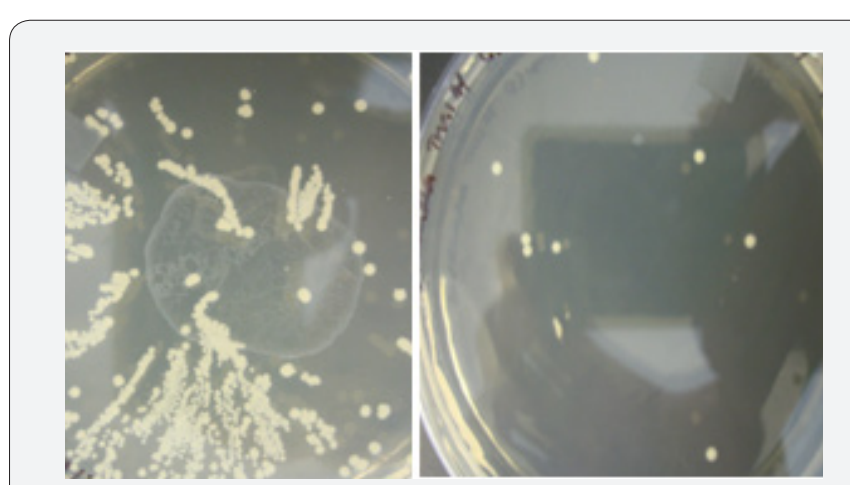

Figure 4: S. aureus applied to surface of discs and treated with hand sanitizer. $10^{-6}$ Serial Dilution Plates of $S$. aureusi: left, + control; right, Purell ${ }^{\mathrm{TM}}$ treated.

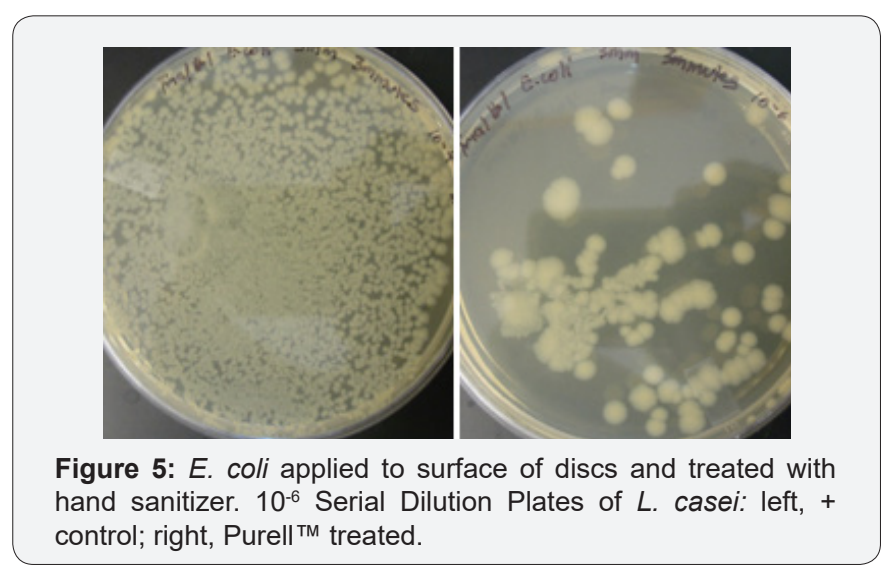

Table 1: Effect of Hand Sanitizer on Biofilm Vitality

\begin{tabular}{|c|c|c|}
\hline Organism & Treatment & CFU at $\mathbf{1 0}^{-4}$ Dilution* \\
\hline \multirow{2}{*}{ S. aureus } & None (+ control) & $105.1 \pm 9.3$ \\
\cline { 2 - 3 } & Purell Tm & $9.3 \pm 1.2$ \\
\hline \multirow{2}{*}{ L. casei } & None (+ control) & $45.4 \pm 3.6$ \\
\cline { 2 - 3 } & Purell Tm & $4.8 \pm 0.8$ \\
\hline \multirow{2}{*}{ E. coli } & None (+ control) & $127.5 \pm 6.7$ \\
\cline { 2 - 3 } & Purell Tm & $28.4 \pm 3.9$ \\
\hline
\end{tabular}

*Data is presented as median \pm standard deviation of 3 trials; - control (disc with no cells) and treatment with $2 \% \mathrm{NaOCl}=0 \mathrm{CFU}$

\section{Discussion}

Athletic mouthguards become colonized by microorganisms after a certain period in the mouth. Previous studies have reported that these appliances become contaminated by several oral microorganism that may be involved in oral and systemic diseases [14]. Although dentists usually recommend at-home disinfection of dentures by immersion in antimicrobial agents for a certain length of time [15] data is lacking concerning the effectiveness of antimicrobials on bacteria attached to these appliances. In addition, in contrast to dentures, there is no emphasis on disinfection of mouthguards either at home or at the arena.

Bacteria with pathogenic potential, L. casei, S. aureus, and E. coli, were selected for this study. L. casei is characteristically known to lead to the progression of carious lesions, and bacteremia, meningitis, and endocarditis have been reported, particularly in immunocompromised patients [16]. S. aureus causes several diseases, such as pneumonia, sepsis, abscesses, infective endocarditis, and osteomyelitis and MRSA [7]. E. coli is an important cause of diarrhea, urinary tract infections, and septicemia [17].

Immersion of discs into sodium hypochlorite 2\% (Chlorox, bleach, $\mathrm{NaOCl}$ ) for $20 \mathrm{sec}$ was considered the gold standard for disinfection from bacteria. $\mathrm{NaOCl}$ is widely used as the main root canal irritant because of its broad antimicrobial activity in endodontics. It is an also a low-cost method to disinfect an appliance [4]. Da Silva et al. [18] investigated the effectiveness of different solutions for disinfecting acrylic resin specimens contaminated with Streptococcus mutans, S. aureus, and E. coli. They found $2 \% \mathrm{NaOCl}$ to be 
the best antimicrobial agent against the tested microorganisms. This result is supported by Salvia et al. [19]. However, although the use of $\mathrm{NaOCl}$, is an effective and low cost methods of sterilization, it is not applicable to use in the locker room or on the playing field.

In this study, we evaluated the efficacy of an alternative protocol-application of Purell ${ }^{\mathrm{TM}}$ - for disinfection of mouthguard specimens compared with the gold standards of chlorox application. Disinfection means to eliminate most harmful microorganisms from surfaces or objects. Purell ${ }^{\mathrm{TM}}$ reduced the levels of all bacteria but did not eliminate the microorganisms completely. The efficacy of Purell in this instance, i.e. it disinfects but does not sterilize, may be explained by the fact that the active ingredient, alcohol, is dispersed in a viscous carrier glycerol, which may not allow contact with all the organisms on the specimen. Also, the concentration of ethanol, at 29\%, is low. Ethanol destroys the membranes of most bacteria on contact. In the same way, the discs were only immersed for 20 seconds, equivalent to the time used for hand sanitation. Longer immersions may eliminate the bacteria altogether. Purell ${ }^{\mathrm{TM}}$ is used almost universally in public facilities such as schools, clinics, and hospitals. It evaporates rapidly, leaves no after taste, and is not toxic to soft tissues [20]. In conclusion, this study supports the use of hand sanitizer for the disinfection of athletic mouthguards that is convenient to use at the athletic site. This in vitro study demonstrates the susceptibility of S. aureus, E. coli, and L. casei to hand sanitizer (Purell ${ }^{\mathrm{TM}}$ ) and demonstrates that it disinfects the surfaces of acrylic specimens of mouthguards.

\section{References}

1. Glass RT (1992) The infected toothbrush, the infected denture, and transmission of disease: A review. Compendium 13(7): 592, 594, 596598.

2. Glass RT, Conrad RS, Kohler GA, Warren AJ, Bullard JW (2011) Microbiota found in protective athletic mouthguards. Sports Health 3(3): 244-248.

3. Sreenivasan PK, Mattai J, Nabi N, Xu T, Gaffar A (2004) A simple approach to examine early microbial formation biofilm and effects of treatments. Oral Microbiologhy and Immunology 19(5): 297-302.

4. Glass RT, Bullard J, Goodson L, Conrad R (2001) Microbial contamination of protective mouth-guards in hockey players: an in vivo study. Compendium Continuing Education Dentistry 22: 1093-1108.
5. Passariello C, Puttini M, Iebba V, Pera P, Gigola P (2012) Influence of oral conditions on colonization by highly toxigenic Stapylococus aureus strains. Oral Dis 18(4): 402-409.

6. Glass RT, Wood CR, Bullard JW, Conrad RS (2007) Possible disease transmission by contaminated mouthguards in two young football players. Gen Dent 55(5): 436-440.

7. Smith AJ, Jackson MS, Bagg J (2001) The ecology of Staphylococcus species in the oral cavity. J Med Microbiol 50(11): 940-945.

8. Patel A, Fischer S, Calfee R, Plante M, Fadale P (2007) Locker room acquired methicillin-resistant Stapylococcus aureus. Orthopedics 30(7): 532-535.

9. Weber K (2009) Commnunity-asssociated methicillin-resistant Staphylococcus aureus infections in the athlete. Sports Health 1(5): 405-410.

10. Johnson DL (2009) Locker room acquired MRSA. Orthopedics 32(3): 180-184.

11. Dills SS, Olshan AM, Goldner S, Brogdon C (1988) Comparison of the antimicrobial capability of an abrasive paste and chemical-soak denture cleaners. Journal of Prosthetic Dentistry 60(4): 467-470.

12. Welch K, Cai Y, Stromme M (2012) A Method for Quantitative Determination of Biofilm Viability. J Funct Biomater 3(2): 418-431.

13. Loesche WJ, Straffon LH (1979) Longitudinal investigation of the role of Streptococcus mutans in human fissure decay. Infect Immun 26(2): 498-507.

14. Lessa FCR, Enoki C, Ito IY, Matsumoto MAN, Faria G, Nelson-Fiho P. (2007) In vivo evaluation of bacterial contamination and disinfection of acrylic baseplates of removable orthodontic appliances. Am J Orthod Dentofacial Orthop 131(6): 705.e11-7.

15. Pavarina AC, Pizzolitto AC, Machado AL, Vergani CE, Giampaolo ET (2003) An infection control protocol: effectiveness of immersion solutions to reduce the microbial growth on dental prostheses. J Oral Rehabil 30(5): 532-536.

16. Salvana EMT, Frank M (2006) Lactobacillus endocarditis: case report and review of cases reported since 1992. J Infect 53(1): e5-e10.

17. Kaper JB, Nataro JP, Mobley HL (2004) Pathogenic Escherichia coli. Nat Rev Microbiol 2(2): 123-140.

18. Da Silva FC, Kimpara ET, Mancini MNG, Balducci I, Jorge AOC, et al. (2008) Effectiveness of six different disinfectants on removing five microbial species and effects on the topographic characteristics of acrylic resin. J Prosthodont 17(8): 627-633.

19. Salvia AC, Matilde Fdos S, Rosa FC, Kimpara ET, Jorge AO, et al. (2013) Disinfection protocols to prevent cross-contamination between dental offices and prosthetic laboratories. J Infect Public Health 6(5): 377-382.

20. Purell ${ }^{\mathrm{TM}}$ Professional Surface Disinfectant Technical Bulletin

\section{Your next submission with Juniper Publishers} will reach you the below assets

- Quality Editorial service

- Swift Peer Review

- Reprints availability

- E-prints Service

- Manuscript Podcast for convenient understanding

- Global attainment for your research

- Manuscript accessibility in different formats

( Pdf, E-pub, Full Text, Audio)

- Unceasing customer service

Track the below URL for one-step submission

https://juniperpublishers.com/online-submission.php 